\title{
In vitro Screening of Native Banana Rhizospheric Microbes and Endophytes of Assam against Fusarium oxysporum f. sp. cubense
}

\author{
Neethi Baruah", Ashok Bhattacharyya, R. Thangavelu and K. C. Puzari \\ Regional Agricultural Research Station, Assam Agricultural University, Diphu, \\ Assam-782462, India \\ *Corresponding author
}

\section{A B S T R A C T}

\begin{tabular}{|l|}
\hline Ke y w or d s \\
$\begin{array}{l}\text { Native, rhizospheric } \\
\text { microbes, } \\
\text { endophytes, banana }\end{array}$ \\
\hline Article Info \\
\hline $\begin{array}{l}\text { Accepted: } \\
18 \text { May } 2018 \\
\text { Available Online: } \\
\text { 10 June } 2018\end{array}$ \\
\hline
\end{tabular}

\section{Keywords}

Native, rhizospheric microbes, tes, banana

\section{Introduction}

The Fusarium oxysporum f. sp. cubense (Foc) is a devastating fungus causing Fusarium wilt in banana. The fungus infects the roots of banana plants, colonizes the vascular system of the rhizome and pseudostem. The infected plant induces characteristic wilting symptoms mostly after 5-6 months of planting and the symptoms are expressed both externally and internally (Wardlaw, 1961, Stover, 1962). The challenging part of the fungus is that it survives in soil for up to 30 years as chlamydospores in infested plant material or in the roots of alternative hosts (Ploetz, 2000). Since the discovery of Fusarium wilt of

\begin{abstract}
A total of 30 native rhizospheric microbes and 7 endophytes had been isolated and purified from rhizospheric soil samples and from roots of healthy banana plants, collected from different banana growing areas of Assam. The screening of 37 rhizospheric microbes and endophytes against Fusarium oxysporum f. sp. cubense was performed with the help of dual culture technique. The efficacy of the rhizospheric microbes and endophytes were the perd at different intervals from 24 to 120 hours. It was observed that out of 37 isolates, the per cent reduction in growth of Fusarium oxysporum f. sp. cubense after 120 hours of inoculation was found more than $70 \%$ in case of 10 rhizospheric microbes. Of which 3 rhizospheric microbes performed better with a per cent reduction in growth above $80 \%$. However, not a single endophytes could be found promising in inhibition the growth of Fusarium oxysporum f. sp. cubense. The per cent reduction of growth was recorded minimum $47.3 \%$ in endophytes against $86.44 \%$ in rhizospheric microbes.
\end{abstract}

banana, various control strategies like soil fumigation (Herbert and Marx, 1990), fungicides (Lakshmanan et al., 1987), crop rotation (Hwang, 1985, Su et al., 1986), flood -fallowing (Wardlaw, 1961, Stover, 1962) and organic amendments (Stover, 1962) have been evolved and attempted, yet, the disease could not be controlled effectively except by planting of resistant cultivars (Moore et al., 1999). Planting of resistant varieties also cannot be implemented successfully because of consumer preference (Viljoen, 2002). Under these circumstances, use of antagonistic microbes which protect the plants from pathogen and promote plant growth by colonizing and multiplying in both 
rhizosphere and plant system has been proved to be a potential alternative approach for the management of Fusarium wilt of banana. Biological control of Fusarium wilt disease has already become an increasingly popular disease management consideration because of its environmental friendly nature (Weller et al., 2002; Fravel et al., 2003). Biological control of soil borne diseases caused especially by Fusarium oxysporum is well documented (Marois et al., 1981; Sivan and Chet, 1986; Larkin and Fravel, 1998; Thangavelu et al., 2004).

Several reports have demonstrated the successful use of different species of Trichoderma, Pseudomonas, Streptomyces, non-pathogenic Fusarium $(\mathrm{np} F o)$ of both rhizospheric and endophytic in nature against Fusarium wilt disease under both glass house and field conditions (Lemanceau and Alabouvette, 1991, Alabouvette et al., 1993, Larkin and Fravel, 1998, Weller et al., 2002, Sivamani and Gnanamanickam, 1988, Thangavelu et al., 2001, Rajappan et al., 2002, Getha et al., 2005, Pushpavathi et al., 2016). Biological control of soil plant pathogens by antagonistic microorganisms is a potential nonchemical means of biocontrol agent against Plant diseases. In the present study efficacy of native potential rhizospheric microbes from banana rhizospheric soil has been tested against Foc in vitro.

\section{Materials and Methods}

\section{Isolation of Foc}

The isolation of the pathogen was carried when the strands have dried. Small sections (3-6 $\mathrm{mm}$ long) of dry discoloured vascular strands were submerged into petri- plates with $1 / 4$ strength PDA amended with an antibacterial agent streptomycin@ $1.2 \mathrm{ml} / 240 \mathrm{ml}$ PDA. Generally, Fusarium growth appeared from the strands in 2 to 4 days. Single-spore (monoconidial) cultures were prepared from each isolates (Perez Vincent et al., 2014).

\section{Single-spore isolation for pure culture of Foc isolates}

The single spore isolation of Foc was followed after Pérez-Vicente et al., 2014. The single spore isolation of the fungus was obtained by either dilution plating or streaking. In this method, a small scrape of sporulating hyphae collected from cultures grown on $1 / 4$ strength PDA plates and dissolved in $10 \mathrm{ml}$ sterile distilled water in test tubes. From the initial spore suspension, a series of dilutions were prepared. One $\mathrm{ml}$ of each of the dilution series was then streaked onto water agar and incubated with the lid up overnight at $25^{\circ} \mathrm{C}$. The plates were viewed for germination of conidia. Germinated single conidia were cut from water agar with a surface sterilized scalpel and transferred to new plates of PDA of $1 / 4$ strength. Cultures of the fungus growing on PDA medium exhibit abundant fluffy aerial mycelium after 2 days and produce abundant conidia. Additionally, single-spore cultures could also be obtained by dissecting the very tip of single growing hyphae from an older culture grown on PDA. Each single spore isolate was grown on filter paper overlaid on half strength PDA. The colonized filter paper was lifted from the agar plate, dried and stored at $4^{0} \mathrm{C}$ until further use.

\section{Collection, isolation and pure culture of Rhizospheric Microbes (RM)}

The rhizospheric soil samples were collected from the rhizosphere of healthy banana plants from different banana growing locations of Assam (cv. Malbhog). 5g soil samples were collected randomly from a field and mixed together for a composite sample and brought to laboratory for isolation of RMs having antagonistic property. For isolation of rhizospheric microbes, the protocol described 
by (Thangavelu and Gopi, 2015) as given below was followed.

One gram of rhizospheric soil collected from different cultivars of banana was transferred to $250 \mathrm{ml}$ conical flasks containing $100 \mathrm{ml}$ of sterile distilled water. The flask was placed in rotary shaker for $10 \mathrm{~min}$ at $120 \mathrm{rpm}$ to dissolve the soil thoroughly. From this, $1 \mathrm{ml}$ of the supernatant was taken and serially diluted upto $10^{-5}$ dilutions. One $\mathrm{ml}$ of the dilution such as $10^{-3}, 10^{-4}$ and $10^{-5}$ was poured at the centre of sterilized petri plates. Onto such plates, media was poured and rotated clockwise and anticlockwise. For isolating fungal rhizospheric microbial culture potato dextrose agar (PDA) medium is used amended with cyclohexamide to suppress the emergence of bacteria. Finally the plates were incubated at $28^{0} \mathrm{C}$ for 2 days and observed for emerging colonies. Colonies were purified and glycerol stock of each isolate was maintained at $-80^{\circ} \mathrm{C}$ for future use. Each fungal colony was purified by single spore isolation technique.

\section{Isolation and pure culture of Endophytes (EP)}

For isolation of EPs the protocol described by (Thangavelu and Gopi, 2015) as given below was followed. Banana EPs were isolated from roots of banana germplasm collected from different banana (cv. Malbhog) growing pockets of Assam. The young roots (both from healthy and wilted plants) were selected for collection. The samples of roots were thoroughly washed with tap water to remove dust and soil particles. Then, $5 \mathrm{~g}$ of these roots individually immerged in $70 \%$ ethanol for 3 minutes, followed by washing with fresh sodium hypochlorite $(2.5 \%)$ solution for 5 minutes, rinse with $70 \%$ ethanol for 30 seconds and subsequently washed five times with sterile distilled water. The aliquots of the sterile distilled water used in the final rinse were spread on tryptic soy agar (TSA) medium plates to confirm the successful sterilization process and the isolates were of endophytic origin. The samples were macerated using sterile mortar and pestle using $1 \mathrm{ml}$ of sterile distilled water and each sample was serially diluted in test tubes containing $9 \mathrm{ml}$ of sterile distilled water. The dilutions such as $10^{-3}, 10^{-4}$ and $10^{-5}$ were plated separately on PDA. The plates were then incubated at $28^{\circ} \mathrm{C}$ for 3 days and observed for the emergence of endophytes and each colony obtained was sub-cultured for further evaluation.

\section{Testing the efficacy of native banana RMs and EPs against Foc}

All the native RMs and EPs obtained were screened against Foc pathogen by dual culture plate assay (Dennis and Webster, 1971) Per cent inhibition of mycelial growth of the pathogen was calculated using the formula suggested by Vincent and Budge (1990). A 10 $\mathrm{mm}$ diameter mycelia disc was cut from a 5 day old culture of Foc pathogen and placed at $1 \mathrm{~cm}$ from the inner edge of $9 \mathrm{~cm}$ petri dishes containing PDA agar medium. Each bacterial and fungal antagonist was either streaked or inoculated on the opposite side of the Foc mycelia disc and incubated at $28^{\circ} \mathrm{C}$ for $5-7$ days. The PDA medium containing Foc alone was maintained as control and three replicates were maintained. The growth of the pathogen and the per cent reduction over control was calculated.

Growth in control- growth in treatment Per cent reduction

Over control $(\%)=$ Growth in control

The design followed was Completely Randomized design (CRD) with five replications and three plates per replication was maintained. 


\section{Results and Discussion}

\section{Isolation of Foc}

The fungus exhibited white with purple tinge colony colour, circular shape and smooth margin with abundant aerial cottony mycelia when grown on $1 / 4$ strength PDA. Microscopic observation revealed that Microconidia (10-12 $\times 2.4-3.0 \mu \mathrm{m}$ ), one or two celled, oval to kidney shaped (one or no septation), Macroconidia $(27-30 \times 3.4-3.6 \mu \mathrm{m})$, four celled (3 septa), and sickle-shaped with attenuated tip and borne on foot shaped basal cell were observed. Chlamydospores $(7-9 \mu \mathrm{m}$ dia) both terminal and intercalary with globose shape are formed singly or in pairs in hyphae.

Based on the above cultural and morphological characters the fungus was identified and confirmed as Fusarium oxysporum f.sp cubense after Booth (1971). The pathogenicity of Foc was confirmed by Koch's postulation.

\section{Collection, isolation and pure culture of native RMs}

In an attempt to isolate potential native RMs against Foc, rhizospheric soil samples were collected from different banana growing areas of Assam such as Dibrugarh, Diphu, Sarupeta, Madang, Boko, Dhenubhanga, Dudhnoi, Rangsipara, Shingra, Kukurmara, Bartari and Gossaigoan covering three agro climatic zones. The collected samples were brought to laboratory for isolation, purification and identification of potential rhizospheric microbes. A total of 30 native RM were isolated and purified from 206 soil samples collected. On the other side, a total of 7 EP were also isolated from 110 root samples. The study on the efficacy of the $37 \mathrm{RM}$ and EP isolates against Foc was studied in vitro for their potentiality to inhibit/suppress Foc growth (diameter in $\mathrm{cm}$ ).
The study was recorded at 5 intervals ranging from 24 to 120 hours of inoculation of Foc varied significantly with that of control at all the intervals (Table 1). The observation was recorded upto 120 hours of inoculation as full growth of Foc was observed under control. An increasing trend in the per cent growth reduction of Foc was observed under different treatments at various intervals.

The growth of Foc after 24 hours of inoculation was $0.99 \mathrm{~cm}$ under RM 05, which differed significantly from all other treatments. The effect of RM 05 was followed by RM 76 with a growth of $1.03 \mathrm{~cm}$. Next, RM 76 was followed by RM 03 with a growth of $1.04 \mathrm{~cm}$. The per cent reduction in growth under RM 05 was $55 \%$ followed by RM 76 with a per cent reduction of $53.18 \%$. Further, RM 76 was followed by RM 03 with 52.75\%.

Next, the growth of Foc after 48 hours of inoculation was $1.64 \mathrm{~cm}$ under RM 05, which differed significantly from all other treatments. The effect of RM 05 was followed by RM 76 with a growth of $1.66 \mathrm{~cm}$. Next, RM 76 was followed by RM 03 with a growth of $1.69 \mathrm{~cm}$. The per cent reduction in growth under RM 05 was $59 \%$ followed by RM 76 with a per cent reduction of $58.50 \%$. Further, RM 76 was followed by RM 03 with $57.75 \%$. Similar observations were recorded after 72 and 96 hours of inoculation.

After 120 hours of inoculation, the growth of Foc was $1.03 \mathrm{~cm}$ under RM 05, which differed significantly from all other treatments. The effect of RM 05 was followed by RM 76 with a growth of $1.36 \mathrm{~cm}$.

Thereafter, RM 76 was followed by RM 03 with a growth of $1.41 \mathrm{~cm}$. The per cent reduction in growth under RM 05 was $86.44 \%$ followed by RM 76 with a per cent reduction of $82.10 \%$ which was followed by RM 03 with a per cent reduction of $81.44 \%$. 
Table.1 Effect of rhizospheric microbes on growth of Foc

\begin{tabular}{|c|c|c|c|c|c|c|c|c|c|c|}
\hline \multirow[t]{2}{*}{ Treatment } & $\begin{array}{l}\text { Growth } \\
\text { of Foc } \\
\text { after } \\
\text { (dia in } \\
\text { cm) }\end{array}$ & \multirow[t]{2}{*}{ *PRG } & $\begin{array}{l}\text { Growth } \\
\text { of Foc } \\
\text { after } \\
\text { (dia in } \\
\text { cm) }\end{array}$ & \multirow[t]{2}{*}{ *PRG } & \multirow[t]{2}{*}{$\begin{array}{l}\text { Growth } \\
\text { of Foc } \\
\text { after } \\
\text { (dia in } \\
\text { cm) } \\
\mathbf{7 2} \text { hrs }\end{array}$} & \multirow[t]{2}{*}{ *PRG } & \multirow[t]{2}{*}{$\begin{array}{l}\text { Growth } \\
\text { of Foc } \\
\text { after (dia } \\
\text { in } \mathrm{cm} \text { ) } \\
\mathbf{9 6} \text { hrs }\end{array}$} & \multirow[t]{2}{*}{$\begin{array}{l}\text { *PR } \\
\text { G }\end{array}$} & \multirow[t]{2}{*}{$\begin{array}{l}\text { Growth } \\
\text { of Foc } \\
\text { after } \\
\text { (dia in } \\
\text { cm) } \\
\mathbf{1 2 0} \text { hrs }\end{array}$} & \multirow[t]{2}{*}{ *PRG } \\
\hline & $24 \mathrm{hrs}$ & & $48 \mathrm{hrs}$ & & & & & & & \\
\hline \multicolumn{11}{|c|}{ Rhizospheric microbes } \\
\hline RM 01+Foc & 1.09 & 50.09 & 1.72 & 57.00 & 2.60 & 50.00 & 2.87 & 52.16 & 1.55 & 79.60 \\
\hline RM 03+Foc & 1.04 & 52.72 & 1.69 & 57.75 & 2.27 & 56.34 & 2.71 & 54.83 & 1.41 & 81.44 \\
\hline RM 04+Foc & 1.06 & 51.81 & 1.71 & 57.25 & 2.24 & 57.23 & 2.85 & 52.50 & 1.56 & 79.47 \\
\hline RM 05+Foc & 0.99 & 55.00 & 1.64 & 59.00 & 2.19 & 57.88 & 2.34 & 61.00 & 1.03 & 86.44 \\
\hline RM 9+ Foc & 1.25 & 42.72 & 2.30 & 40.00 & 3.80 & 26.92 & 3.40 & 43.33 & 2.29 & 69.86 \\
\hline RM 12+ Foc & 1.24 & 43.63 & 2.32 & 42.00 & 3.50 & 32.69 & 3.48 & 42.00 & 2.30 & 69.73 \\
\hline RM 19+Foc & 1.21 & 45.00 & 1.91 .90 & 52.552 & 2.632 .63 & 49.42 & 3.133 .1 & 47.83 & 1.44 & 81.18 \\
\hline RM 22+Foc & 1.20 & 45.45 & 1.98 & 50.50 & 2.79 & 46.34 & 3.38 & 43.66 & 1.86 & 75.52 \\
\hline RM 25+ Foc & 1.30 & 40.90 & 2.43 & 39.25 & 3.60 & 30.76 & 3.55 & 40.83 & 2.29 & 69.86 \\
\hline RM 30+ Foc & 1.30 & 40.90 & 2.46 & 38.50 & 3.80 & 26.92 & 3.58 & 40.33 & 2.30 & 69.73 \\
\hline RM 40+ Foc & 1.26 & 42.72 & 2.38 & 40.50 & 3.60 & 30.76 & 3.50 & 41.66 & 2.39 & 68.00 \\
\hline RM 45+ Foc & 1.29 & 41.36 & 2.40 & 40.00 & 3.50 & 32.69 & 3.53 & 41.16 & 2.30 & 69.73 \\
\hline RM 51+ Foc & 1.36 & 38.18 & 2.49 & 37.75 & 3.60 & 30.76 & 3.60 & 40.00 & 2.39 & 68.00 \\
\hline RM 65+Foc & 1.22 & 44.54 & 2.00 & 50.00 & 2.70 & 48.07 & 3.09 & 48.50 & 1.51 & 80.13 \\
\hline RM 69+ Foc & 1.39 & 36.81 & 2.50 & 37.50 & 3.90 & 25.00 & 3.64 & 39.33 & 2.40 & 68.42 \\
\hline RM 76+Foc & 1.03 & 53.18 & 1.66 & 58.50 & 2.26 & 57.19 & 2.46 & 59.00 & 1.36 & 82.10 \\
\hline RM 88+ Foc & 1.40 & 36.36 & 2.54 & 36.50 & 3.80 & 26.92 & 3.68 & 38.66 & 2.48 & 67.36 \\
\hline RM 90+ Foc & 1.44 & 34.54 & 2.58 & 35.50 & 3.60 & 30.76 & 3.70 & 38.33 & 2.50 & 67.10 \\
\hline RM 97+ Foc & 1.49 & 32.27 & 2.60 & 35.00 & 3.70 & 28.84 & 3.76 & 37.33 & 2.54 & 66.57 \\
\hline RM 103+Foc & 1.08 & 50.90 & 1.67 & 58.50 & 2.37 & 54.42 & 2.65 & 55.83 & 1.55 & 79.60 \\
\hline RM 116+Foc & 1.09 & 50.45 & 1.85 & 53.75 & 2.60 & 50.00 & 3.23 & 46.16 & 1.91 & 74.86 \\
\hline RM 129+Foc & 1.50 & 31.81 & 2.63 & 34.25 & 3.60 & 30.76 & 3.80 & 36.66 & 2.59 & 65.92 \\
\hline RM 153+Foc & 1.54 & 30.00 & 2.67 & 33.25 & 3.60 & 30.76 & 3.87 & 35.50 & 2.60 & 65.78 \\
\hline RM 160+Foc & 1.58 & 28.18 & 2.70 & 32.50 & 3.70 & 28.84 & 3.90 & 35.00 & 2.70 & 64.47 \\
\hline RM 173+Foc & 1.60 & 27.27 & 2.74 & 31.50 & 3.90 & 25.00 & 4.00 & 33.33 & 2.80 & 63.15 \\
\hline RM 175+Foc & 1.63 & 25.90 & 2.78 & 30.50 & 3.70 & 28.84 & 4.20 & 30.00 & 2.90 & 61.84 \\
\hline RM 189+Foc & 1.66 & 24.54 & 2.80 & 30.00 & 3.60 & 30.76 & 4.30 & 28.33 & 3.00 & 60.52 \\
\hline RM 200+Foc & 1.69 & 23.18 & 2.82 & 29.50 & 3.90 & 25.00 & 4.50 & 25.00 & 3.20 & 57.89 \\
\hline RM 205+Foc & 1.70 & 22.72 & 2.85 & 28.75 & 3.80 & 26.92 & 4.60 & 23.33 & 3.40 & 55.26 \\
\hline RM 206+Foc & 1.72 & 21.81 & 2.88 & 28.00 & 3.70 & 28.84 & 4.70 & 21.66 & 3.90 & 48.68 \\
\hline \multicolumn{11}{|l|}{ Endophytes } \\
\hline PTH-E +Foc & 1.75 & 20.45 & 2.90 & 27.50 & 3.70 & 28.84 & 4.78 & 20.33 & 4.00 & 47.36 \\
\hline RNG1-E+Foc & 1.78 & 19.09 & 3.00 & 25.00 & 3.90 & 25.00 & 4.90 & 18.33 & 4.20 & 44.73 \\
\hline GOS-E+Foc & 1.66 & 18.18 & 3.20 & 20.00 & 3.80 & 26.92 & 4.20 & 30.00 & 5.00 & 34.21 \\
\hline RNG2-E+Foc & 1.69 & 24.54 & 2.85 & 28.75 & 3.60 & 30.76 & 4.30 & 28.33 & 5.60 & 26.31 \\
\hline GOS5-E+Foc & 1.70 & 23.18 & 2.80 & 30.00 & 3.60 & 30.76 & 4.00 & 33.33 & 4.00 & 47.36 \\
\hline ROU-E+Foc & 1.72 & 22.72 & 2.70 & 32.50 & 3.90 & 25.00 & 4.60 & 23.33 & 5.00 & 34.21 \\
\hline BRT-E+Foc & 1.69 & 23.18 & 2.90 & 27.50 & 3.80 & 26.92 & 4.70 & 21.66 & 4.20 & 44.73 \\
\hline Control & 2.20 & - & 4.00 & - & 5.20 & - & 6.00 & - & 7.60 & - \\
\hline C.D (0.05) & 0.007 & - & 0.086 & - & 0.020 & - & 0.017 & - & 0.011 & - \\
\hline
\end{tabular}


Fig.1 Growth of Foc under three best treatments after 72 hours of inoculation
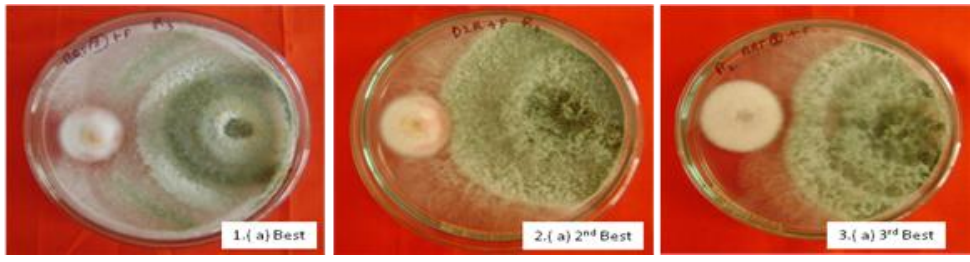

Fig.2 Growth of Foc under three best treatments after 120 hours of inoculation

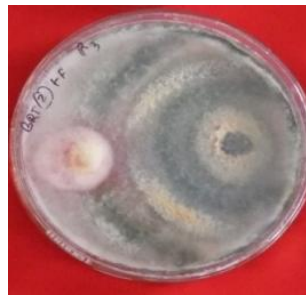

(a) Best

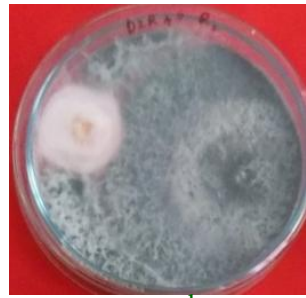

(b) $2^{\text {nd }}$ Best

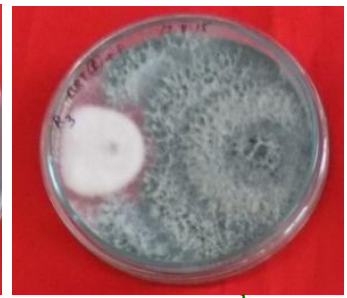

(c) $3^{\text {rd }}$ Best

Fig.3 Per cent growth reduction of Foc at different intervals

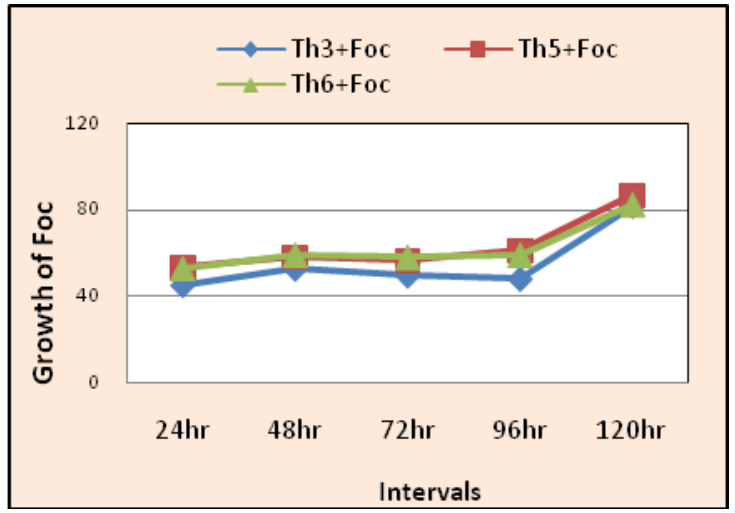

It has also been observed that the RMs were found to be more effective with that of EPs. In case of the least effective RMs (RM 206), the per cent growth reduction of Foc was observed $48.68 \%$ against the best effective EPs (PTH-E) which recorded only $47.36 \%$ growth inhibition of Foc. On the other hand, the effect of ten RMs was found to be promising with capabilities of per cent growth reduction of Foc more than $70 \%$. Based on such result, the EPs were not considered for further studies. Moreover, the RMs with a capability of more than 80 per cent Foc growth reduction were considered for further studies.
The comparative growth of 3 best RMs after 72 and 120 hours after inoculation (Fig. 1 and $2)$. The variations in the per cent growth reduction of Foc under best three treatments were presented in Fig. 3

The rhizosphere encompasses the millimeters of soil surrounding a plant root where complex biological and ecological processes occur. The growth of banana plants is closely related to the bio- diversity in the rhizosphere. Under constant supply of normal nutrition, the roots of the banana plants are well developed. The exudates from the root hairs or root tip promote the growth of rhizosphere organisms 
(Bais et al., 2006), which in turn enhance the biodiversity of soil. In our study, 206 rhizospheric soil samples collected from rhizosphere of healthy banana plants adjacent to infected fields from different locations of Assam (cv. Malbhog).

A total of 110 banana root samples were collected from different banana growing locations of Assam adjacent to wilted fields for isolation of EPs. Reports of collection of EPs from healthy as well as diseased plant are available and the report of Cao et al., (2014) indicated that a higher percentage $(50 \%)$ of antagonistic actinomycetes was found in healthy plants, especially in the roots. However, they reported that the EPs isolated from diseased plants had higher degree of diversity. These results are in conformity with the findings of Reiter et al., (2002). In an interesting note Cao et al., (2014) further added that no difference in terms of efficacy was evident amongst the EPs isolated from wilted and healthy plants.

In the present investigation altogether $30 \mathrm{RMs}$ and 7 EPs were collected and their efficacy was tested against Foc. Though the effect of the RMs and EPs varied significantly with that of control at different intervals from 24 hours to 120 hours. After 24 hours the per cent reduction was observed highest $(55 \%)$ in RM 05 followed by RM 76 (53.18\%). Similar trend in reduction percentage was observed under 48, 72, 96 and 120 hours after inoculation with RM 05 was the best followed by RM 76.

Moreover, the per cent reduction in growth of Foc after $120 \mathrm{hr}$ of inoculation was found more than $70 \%$ in case of 10 RMs. And the best 3 were selected for further studies. Not a single endophyte could show their promise for growth inhibition of Foc. The per cent reduction of growth was recorded minimum $47.3 \%$ in EP against $86.44 \%$ in RM.
Probability of the result may be explained by considering which might be due to many reasons, viz., occurrence of lower population densities of endophytes than rhizospheric microbe (Hallmann et al., 1997, Rosenblueth and Martínez-Romero, 2004), shifting of the status of endophytes from endophytic nature to pathogenic depending upon developmental stages of the plant (Stone et al., 2000 and Schulz and Boyle, 2005).

The promising $3 \mathrm{RMs}$ were found to possess similar cultural and morphological characters based on the cultural and morphological characteristics the isolates were identified as Trichoderma spp. after Rifai, 1969 which were further confirmed as Trichoderma harzianum Rifai. at Agharkar Research Institute, Pune.

The result of the present study revealed fair amount of efficacy against Foc in vitro and a large number of reports support our findings (Sundaramoorthy and Balabaskar, 2013, Otadoh et al., 2011, Barari, 2016).

The potentiality of Trichoderma harzianum as one of the most efficient biocontrol agent is considered due to its high reproductive capacity, ability to survive under unfavourable conditions, efficiency in nutrient utilization, capacity to modify the rhizosphere, strong aggressiveness against the pathogenic fungi and efficiency in promoting plant growth and defence mechanisms (Misra and Prasad, 2003).

The result of dual culture test revealed two exceptional RMs- Ceratocystis frimbrata and Rhizopus arrhizus. These two RMs are pathogens causing diseases. But from the experiment it was recorded that they could inhibit the growth of Foc sufficiently as compared to other RMs and EPs. This nature of antagonism may be due to availability of non-pathogenic form of the fungus such as 
non-pathogenic form of Fusarium against Foc. Moreover sometimes pathogens may act as biocontrol agent. There are references of Penicillium sp. acting as biocontrol agent against Phytophthora root rot of Azalea and citrus (Fang and Tsao, 1995). Therefore, further studies on Ceratocystis frimbrata and Rhizopus arrhizus as biocontrol agents may open up new areas of research.

\section{References}

Alabouvette, C.; Lemanceau, P. and Steinberg, C. (1993). Recent advances in the biological control of Fusarium wilts. Pestic. Sci. 37: 365-373.

Barari, H. (2016). Biocontrol of tomato fusarium wilt by trichoderma species under in vitro and in vivo conditions. cercetări agronomice în moldova vol. xlix, no. 1 (165), 91-98.

Booth, C. (1971).The genus Fusarium. Commonwealth Mycological Institute, Kew, Surrey, England, $237 \mathrm{Pp}$.

Chao, X., Penton, C. R., Shen, Z., Zhang, R., Huang, Q., Li, R., Ruan, Y. And Shen, Q. (2015). Manipulating the banana rhizosphere microbiome for biological control of Panama disease. Scientific Reports 5, Article number: 11124

Fang, J.G. and Tsao, P.H. (1995). Efficacy of Penicillium funiculosum as biological control agent against Phytophthora root rots of Azalea and Citrus. Phytopath. 85: 871878.

Fravel, D.; Olivain, C. and Alabouvette, C. (2003). Fusarium oxysporum and its biocontrol. New Phytol. 157: 493-502.

Getha, K.; Vikineswary, S.; Wong, W.H.; Seki, T.; Ward, A. and Goodfellow, M. (2005): Evaluation of Streptomyces sp. strain g10 for suppression of Fusarium wilt and rhizosphere colonization in pot-grown banana plantlets. J. Ind. Microbiol. Biotechnol. 32: 24-32.

Hallmann, J.; Quadt-Hallmann, A.; Mahaffee, W.F. and Kloepper, J.W. (1997). Bacterial endophytes in agricultural crops. Can. J. Microbiol. 43: 895-914.
Herbert, J.A. and Marx, D. (1990). Short-term control of panama disease in south Africa. Phytophyl. 22: 339-340.

Hwang, S.C. (1985). Ecology and control of Fusarium wilt of banana. Plant Prot. Bull. 27: 233-245.

Lakshmanan, P.; Selvaraj, P. and Mohan, S. (1987). Efficiency of different methods for the control of Panama disease. Trop. Pest Mngt. 33: 373-376.

Larkin, R. and Fravel, D. (1998). Efficacy of various fungal and bacterial biocontrol organisms for the control of Fusarium wilt of tomato. Plant Dis. 82: 1022-1028.

Lemanceau, P. and Alabouvette, C. (1991). Biological control of Fusarium diseases by fluorescent Pseudomonas and nonpathogenic Fusarium. Crop Prot. 10: 279286.

Marois, J.J.; Mitchel, D.J. and Somada, R.M. (1981). Biological control of Fusarium crown and root rot of tomato under field condition. Pytopathol. 12: 1257-1260.

Misra, A.K. and Prasad, B. (2003). Trichoderma a genus for biocontrol. In: Biopesticide and Bioagents in Integrated Pest Management of Agriculture Crops, R.P. Shrivastava (ed.) International Book Distribution Co., Lucknow. pp. 811-833.

Otadoh, J. A., Sheila A. Okoth, James Ochanda and James P. Kahindi. (2011). Assessment of trichoderma isolates for virulence efficacy on Fusarium oxysporum F. sp. Phaseoli. Tropical and Subtropical Agroecosystems, 13, $99-107$.

Pérez Vincent, L.; Dita, M.A. and Parte, E.M.L. (2014). Technical Manual Prevention and diagnostic of Fusarium Wilt (Panama disease) of banana caused by Fusarium oxysporum f. sp. cubense Tropical Race 4 (TR4).

Ploetz, R.C. (2000). Panama disease: a classic and destructive disease of banana. Plant Health Prog. 10: 1-7.

Pushpavathi, Y.; Dash, S.N.; Madhavi, N. and Deepika, D. (2016). Biological control of Fusarium wilt disease in Banana with emphasis on Trichoderma spp. and Pseudomonas spp. Plant Arch. 16(1): 5159. 
Rajappan, K.; Vidhyasekaran, P.; Sethuraman, K. and Baskaran, T.L. (2002). Development of power and capsule formations of Pseudomonas fluorescences strain Pf-1 for the control of banana wilt. Zeitschrift fur Pflanzenkrankheiten and Pflanzenschutz 109: 80-87.

Reiter, B.; Pfeifer, U.; Schwab, H. and Sessitsch, A. (2002). Response of endophytic bacterial communities in potato plants to infection with Erwinia carotovora subsp. atroseptica. Appl. Environ. Microbiol. 68: 2261-2268.

Rosenblueth, M. and Martinez, R.E. (2004). Rhizobium etli maize populations and their competitiveness for root colonization. Arch. Microbiol. 181: 337-344.

Schulz, B. and Boyle, C. (2005). The endophytic continuum. Mycol. Res. 109: 661-686.

Sivamani, E. and Gnanamanickam, S.S. (1988). Biological control of Fusarium oxysporum f. sp. cubense in banana by inoculation with Pseudomonas fluorescens. Plant Soil 107: 39.

Sivan, A. and Chet, I. (1986). Biological control of Fusarium spp. in cotton, wheat and muskmelon by Trichoderma harzianum. J. Phytopathol. 116: 39-47.

Stone, J.K.; Bacon, C.W. and White, J.F. (2000). An overview of endophytic mibrobes: Endophytism defined. In: Microbial Endophytes. Bacon, C.W. and White, J.F. (eds.). Marcel Dekker, New York, pp. 3-30.

Stover, R.H. (1962). Fusarial wilt (Panama disease) of bananas and other Musa species. UK: Commonwealth Mycological Institute, p. 117.

Su, H.J.; Hwang, S.C. and Ko, W.H. (1986). Fusarial wilt of Cavendish bananas in Taiwan. Plant Dis. 70: 814-818.
Sundaramoorthy, S. and Balabaskar, P. (2013). Biocontrol efficacy of Trichoderma spp. against wilt of tomato caused by Fusarium oxysporum f. sp. lycopersici. Journal of Applied Biology \& Biotechnology.1 (03), 36-40

Thangavelu, R. and Gopi, M. (2015). Field suppression of Fusarium wilt disease in banana by the combined application of native endophytic and rhizospheric bacterial isolates possessing multiple functions. Phytopathol. Medit. 54: 241-252.

Thangavelu, R.; Palaniswami, A. and Velazhahan, R. (2004). Mass production of Trichoderma harzianum for managing Fusarium wilt of banana. Agri. Ecosys. Environ. 103: 259263.

Thangavelu, R.; Palaniswami, A.; Ramakrrishnan, G.; Sabitha, D.; Muthukrishnan, S. and Velazhahan, R. (2001). Involvement of Fusaric acid detoxification by Pseudomonas fluorescens strain Pf10 in the biological control of Fusarium wilt of banana caused by Fusarium oxysporum $\mathrm{f}$. sp. cubense. J. Plant Dis. Prot. 108: 433445.

Viljoen, A. (2002). The status of Fusarium wilt (Panama disease) of banana in South Africa. South Afr. J. Sci. 98: 341-344.

Wardlaw, C.W. (1961). Banana diseases, including Plaintains and Abaca. Longmans, Green and Co. Ltd, London, p. 648.

Weller, D.M.; Raaijmakers, J.M.; McSpadden Gardener, B.B. and Thomashow, L.S. (2002). Microbial population responsible for specific soil suppressiveness to plant pathogens. Ann. Rev. Phytopathol. 40: 309344.

\section{How to cite this article:}

Neethi Baruah, Ashok Bhattacharyya, R. Thangavelu and Puzari K. C. 2018. In vitro Screening of Native Banana Rhizospheric Microbes and Endophytes of Assam against Fusarium oxysporum f. sp. cubense. Int.J.Curr.Microbiol.App.Sci. 7(06): 1575-1583. doi: https://doi.org/10.20546/ijcmas.2018.706.188 